\title{
THE IMPACT OF AIR RESISTANCE ON THE FUEL CONSUMPTION IN REAL CONDITIONS WITHIN THE TRANSPORT OPERATION
}

This paper presents the impact of air resistance (air resistance) on fuel consumption of the particular vehicle under real traffic conditions. In the introductory and subsequent part of the paper, the individual resistances influencing the moving vehicle are characterized. In the following chapter, the specific factors such as air resistance, driving speed, air temperature and air resistance coefficient in the context of their impact on fuel consumption of the particular vehicle are identified and described; as well as the comparisons of fuel consumption when the vehicle is moving on the highway with closed and open windows under different conditions of road traffic are performed.

Keywords: Air resistance, vehicle's fuel consumption, resistance, driving speed, air temperature, air resistance coefficient.

\section{Introduction}

These days, the significant climate changes have been ongoing on our planet. The most significant ones include the frequent changes in weather and temperatures that achieve long-term records. Thermophilic plants and animals have been found in more and more northern latitudes. The sea levels have been increasing every year. Without the necessary interventions into the human activities, at the end of the century, the sea levels will be higher by one or two meters [1].

Experts attribute these changes to the production of greenhouse gases, and above all carbon dioxide $\left(\mathrm{CO}_{2}\right)$. The transport is one of the main producers of these gases. For the drive of vehicles within transport, the conventional engines with internal combustion whose exhaust gases contain $\mathrm{CO}_{2}$ are utilized particularly. If the vehicle consumes 1 liter of petrol, $2.5 \mathrm{~kg}$ of $\mathrm{CO}_{2}$ is penetrated in the air. For the diesel engines, it is $2.7 \mathrm{~kg}$ of $\mathrm{CO}_{2}$. By the ecologists, this gas is considered to be the most important in terms of the greenhouse effect creation. However, the exhaust gases are not only made up of carbon dioxide, but they contain NOx, incompletely burned carbon represented by $\mathrm{CO}$, unburned hydrocarbons HC, carbon black, sulfur and formaldehyde as well. These substances also have an impact on the greenhouse effect creation and simultaneously, they adversely influence the human body [1 and 2].

\section{Identification of resistances influencing the moving vehicle}

When a vehicle is moving at constant speed, its resistance to motion, termed the tractive resistance, consists of: Air resistance $(A R)$ : Air resistance (wind resistance) depends upon the size and shape of the vehicle - its degree of streamlining- and increases approximately as the square of the speed through the air; Rolling resistance $(R R)$ : This depends mainly upon the nature of the ground, the tires used, the weight of the vehicle, and to a lesser extent, the speed (the last variation is usually ignored); Gradient resistance (GR): This is determined by the steepness of the hill and the weight of the vehicle, which must, in effect, be lifted from the bottom to top; Inertia resistance (IR): To accelerate the car speed it needs a force; this force is represented by the vehicle resistance to change its speed (inertia resistance) [3 and 4].

\subsection{Air resistance}

As long as a vehicle is moving, air resistance (drag or wind resistance) is always present. Aerodynamics effects on vehicle functions are: Directional Control (Driving Safety) [pitching, yaw, and rolling moments] - left and cross wind force; Driving Performance and Fuel consumption [air resistance] - tangential forces; Comfort [wind noises, passenger compartment ventilation,

\footnotetext{
* 1Vladimir Rievaj, ${ }^{2}$ Ondrej Stopka, ${ }^{1}$ Jan Vrabel, ${ }^{1}$ Lenka Mokrickova, ${ }^{3}$ Conrad Schmidt

${ }^{1}$ Department of Road and Urban Transport, Faculty of Operation and Economics of Transport and Communications, University of Zilina, Slovakia

${ }^{2}$ Faculty of Technology, Institute of Technology and Business in Ceske Budejovice, Czech Republic

${ }^{3}$ Technische Hochschule Wildau (FH) Wildau, Germany

E-mail: stopka@mail.vstecb.cz
} 
dirty interior]; Clear Visibility [Dirty windows and lamps, Prevention of windshield misting]; Auxiliary equipment functions [engine cooling, engine compartment ventilation, brake cooling, air conditioning] [4 and 5].

The size of the air resistance can be determined with using the following formula (1):

$$
R_{a}=\frac{1}{2} \cdot \rho \cdot v^{2} \cdot c_{x} \cdot S
$$

where $\rho$ is the instant specific weight of the air $\left[\mathrm{kg} / \mathrm{m}^{3}\right], v$ is the speed of the vehicle (driving speed; velocity) $[\mathrm{m} / \mathrm{s}], c_{x}$ is the air resistance coefficient (drag coefficient or coefficient of influence of the body shape on air resistance) [-], $S$ is the size of the front area of the vehicle $\left[\mathrm{m}^{2}\right]$.

Instant specific weight of the air corresponding to the particular conditions can be determined with using the following formula (2):

$\rho=\rho_{n} \cdot \frac{273}{273+t} \cdot \frac{p}{p_{n}}$

where $\rho_{n}$ is the instant specific weight of the air at temperature $0^{\circ} \mathrm{C}$ and under pressure $0.101325 \mathrm{MPa}$. Under these conditions, its value is $1.29 \mathrm{~kg} / \mathrm{m}^{3}, t$ is the instant air temperature $\left[{ }^{\circ} \mathrm{C}\right], p$ is the instant air pressure [MPa], $p_{n}$ is the normal air pressure [0.101325 MPa].

This indicates that the size of the air resistance is changed proportionally with the driving speed and the air pressure and inversely with the air temperature [6].

\subsection{Rolling resistance}

The rolling resistance of the tires is the second driving resistance that is always present as long as the vehicle is moving. At low speeds on hard pavement, the rolling resistance is the primary motion resistance force. In fact, aerodynamic resistance becomes equal to the rolling resistance only at speeds of 80-100 km/h. For off-highway, level ground operation; the rolling resistance is the only significant retardation force [6].

There are at least seven mechanisms responsible for rolling resistance: 1) energy loss due to deflection of the tire sidewall near the contact area, 2) energy loss due to deflection of the tread elements, 3) scrubbing in the contact patch, 4) tire slip in the longitudinal and lateral directions, 5) deflection of the road surface, 6) air drag on the inside and outside of the tire, 7) energy loss on bumps [6 and 7].

Considering the vehicle as a whole, the total rolling resistance is the sum of the resistance from all the wheels. Its size can be determined with using the following formula (3) [6]:

$$
R_{G}=m \cdot g \cdot \sin \alpha
$$

where $m$ is the vehicle's weight $[\mathrm{kg}], g$ is the acceleration due to gravity $\left[9.81 \mathrm{~m} / \mathrm{s}^{2}\right], \alpha$ is the angle of the road inclination on which the vehicle is moving $\left[{ }^{\circ}\right], \mathrm{f}$ is the coefficient of rolling resistance [-].

The value of the coefficient of rolling resistance depends on many factors: construction of the tire casing; aspect ratio of the tire; radial load of the tire; wheel offset; driving speed (velocity); tire temperature; tire diameter; tire slip; tire inflation pressure [6].

Typical values of the coefficient of rolling resistance under different conditions are shown in Table 1 [6 - 8].

Specific values of the coefficient of rolling resistance

Table 1

\begin{tabular}{|l|c|c|c|}
\hline \multirow{2}{*}{ Vehicle Type } & \multicolumn{3}{|c|}{ Surface Type } \\
\cline { 2 - 4 } & Concrete & Medium Hard & Sand \\
\hline Passenger vehicle & 0.015 & 0.08 & 0.30 \\
\hline Heavy trucks & 0.012 & 0.06 & 0.25 \\
\hline Tractors & 0.02 & 0.04 & 0.20 \\
\hline
\end{tabular}

Source: Authors

\subsection{Gradient resistance}

The gradient resistance (climbing resistance, inclined road force) depends on the angle of the road inclination and the weight of the vehicle.

It is actually the force acting parallel to the road. As long as the vehicle is moving along a sloping surface, the vehicle weight acts at a certain angle to this surface. Therefore, the weight of the vehicle weight is divided to the component perpendicular to the road and the component parallel to the road. The size of the gradient resistance can be determined with using the following formula [6]:

$R_{G}=m \cdot g \cdot \sin \alpha$

where $m$ is the vehicle's weight $[\mathrm{kg}], g$ is the acceleration due to gravity $\left[9.81 \mathrm{~m} / \mathrm{s}^{2}\right], \alpha$ is the angle of the road inclination $\left[{ }^{\circ}\right]$.

\subsection{Inertia resistance}

This force depends on the weight of the vehicle and the value of the vehicle acceleration. Each body resists to change of its motion state and a vehicle is no exception. To change the speed of the vehicle, its engine must expend some energy corresponding to the inertia work required to overcome the inertia resistance [ 6 and 8].

The size of this resistance can be determined with using the following formula (5):

$R_{I}=m \cdot a \cdot \delta$

where $m$ is the vehicle's weight $[\mathrm{kg}], a$ is the acceleration of the vehicle $\left[\mathrm{m} / \mathrm{s}^{2}\right], \delta$ is the coefficient of impact of the rotational mass [-]. 
The size of the coefficient of impact of the rotational mass depends on weight of the engine rotational mass (engine displacement, the method of ignition of the fuel mixture, the number of engine cylinders), gear ratio in the transmission system, weight and size of the wheels and the efficiency of the transmission system [6, 8 and 9].

\section{Identification and description of the specific factors affecting the fuel consumption of the particular vehicle}

As appears from the above, a range of factors affects the vehicle's fuel consumption. In order to determine the impact of the particular resistance, the measurement needs to be set in such a way that the other factors will not be changed. The efficiency of the engine and transmission system is an important factor. To eliminate this impact, all the measurements were performed on the same vehicle in a small period of time in order to avoid the influence of deterioration of the vehicle technical condition. For the purpose of measurements, the vehicle SUZUKI SX4 with the engine displacement of $1,500 \mathrm{~cm}^{3}$ was used. Before the actual measurements, tires were inflated to the recommended pressure and the vehicle technical condition and its adjustment in accordance with the manufacturer's instructions were checked [6 and 9].

\subsection{The impact of the air resistance}

During the vehicle movement, the size of air resistance may vary according to the driving speed (velocity) $v$, change of the air resistance coefficient $c_{x}$, as well as the air temperature. To avoid the height profile impact, the measurements were performed on the same route, and it was necessary to minimize the impact of change in the vehicle driving speed. Journey on the highway meets these conditions best. On the highway, it was possible to achieve the necessary driving speed and maintain it throughout the entire journey section. The measuring section had a length of $6.42 \mathrm{~km}$.

The fuel consumption measurement was started after achieving the required driving speed. In order to minimize the impact of the driver's behavior during the journey, the driving speed was maintained using the cruise control. The wind speed was up to $3 \mathrm{~m} / \mathrm{s}$ and the vehicle windows were closed. The road surface was dry [6 and 10$]$.

\subsection{The impact of the driving speed}

If it was necessary to change the driving speed due to the traffic situation, the measurement was annulled. Thanks to these measures, the driving speed was the only changing parameter. The measurement was performed for the driving speed 110, 120 and $130 \mathrm{~km} / \mathrm{h} \mathrm{[9}$ and 10].

The final fuel consumption obtained from the measurement while the vehicle was traveling on the highway with the closed windows is shown in the following Table 2.

From the obtained results it can be noticed that with increasing the driving speed, the fuel consumption tended to increase. When changing the driving speed from 110 to $120 \mathrm{~km} / \mathrm{h}$, the change represents a value of $109.1 \%$ and the change in the fuel consumption mirrors this change by the growth of $109.6 \%$ of the original consumption. A more significant difference is observed when increasing the driving speed to $130 \mathrm{~km} / \mathrm{h}$, i.e. to $118.2 \%$ of the original value, the fuel consumption increases to $130.8 \%$ of the original value. These values result from the fact that in the formula for calculating the air resistance, the driving speed occurs in the square [10 and 11].

\subsection{The impact of the air temperature}

Air temperature affects the air density (specific weight) and thus as well as the size of air resistance proportionally. For comparison of the fuel consumption, the measurements for the driving speed of $120 \mathrm{~km} / \mathrm{h}$ and air temperatures at $34{ }^{\circ} \mathrm{C}$ and 10 ${ }^{\circ} \mathrm{C}$ were performed. The results of measurements are shown in Table 3 [4, 6, 9 and 11].

An air temperature drop of $24{ }^{\circ} \mathrm{C}$ caused an increase in fuel consumption to $108.8 \%$ at the same driving speed.

The final fuel consumption on the highway with the closed windows

Table 2

\begin{tabular}{|c|c|c|c|c|}
\hline \multicolumn{2}{|c|}{ Driving speed } & \multicolumn{2}{|c|}{ Fuel consumption } & Air temperature \\
\hline$[\mathrm{km} / \mathrm{h}]$ & $\begin{array}{c}\text { Index of increase in speed compared to } \\
\text { the speed } 110 \mathrm{~km} / \mathrm{h}\end{array}$ & $\begin{array}{c}\text { Index of increase in fuel } \\
\text { consumption compared to the } \\
\text { speed } 110 \mathrm{~km} / \mathrm{h}\end{array}$ & $1.100 \mathrm{~km}]$ \\
\hline 110 & 1.00 & 5.2 & 1.00 & $34^{\circ} \mathrm{C}$ \\
\hline 120 & 1.091 & 5.7 & 1.096 & $34^{\circ} \mathrm{C}$ \\
\hline 130 & 1.182 & 6.8 & $34{ }^{\circ} \mathrm{C}$ \\
\hline
\end{tabular}

Source: Authors 


\section{COMMNICOIIONS}

The fuel consumption for the driving speed of $120 \mathrm{~km} / \mathrm{h}$ on the highway with the closed windows

Table 3

\begin{tabular}{|c|c|c|c|}
\hline Driving speed $[\mathrm{km} / \mathrm{h}]$ & Fuel consumption $[1 / 100 \mathrm{~km}]$ & Index of increase in fuel consumption & Air temperature $\left[{ }^{\circ} \mathrm{C}\right]$ \\
\hline 120 & 5.7 & & \multirow{2}{*}{1.088} \\
\cline { 1 - 2 } & 6.2 & & 10 \\
\hline
\end{tabular}

Source: Authors

\subsection{The impact of the air resistance coefficient change}

Especially in summer, drivers travel with the open windows in order to maintain an acceptable air temperature inside the vehicle. Vehicle's open window affects the airflow around the vehicle and influences the air resistance coefficient. For comparison, the journeys on the highway at the same driving speed and at the same ambient temperature were performed. One journey took place with the closed windows; during the second journey, the driver's window was open (ajar). The results are shown in the following Table 4 [4 and 10].

The travel with the open window represents an increase in fuel consumption of $1.9 \%$ at a speed of $100 \mathrm{~km} / \mathrm{h}$, of $1.8 \%$ at a speed of $120 \mathrm{~km} / \mathrm{h}$. The difference is negligible and this fact corresponds with the experimental data obtained when measuring the impact of driving speed on fuel consumption. At a speed of $130 \mathrm{~km} / \mathrm{h}$, the fuel consumption was increased by $2.9 \%$ [10 and 11].

\subsection{The journey on the 1st class road}

The fuel consumption of the vehicle under the normal traffic conditions, where the driving speed is limited by other road users and traffic regulations, already includes the inertia resistances and involves a change of driving speed. The comparison of fuel consumption was performed on the 1st class road between towns Bytca and Zilina. The driver tried to drive at a steady speed, where some journeys took place in dense traffic and driving speed was limited by the driving speed of other vehicles and did not exceed $80 \mathrm{~km} / \mathrm{h}$; and there were also the journeys without any other vehicles and the driving speed was therefore limited up to 90 $\mathrm{km} / \mathrm{h}$. On the road, the limitations in driving speed up to $50 \mathrm{~km} / \mathrm{h}$ (twice) and up to $70 \mathrm{~km} / \mathrm{h}$ (twice) occurred. The results of the measurement are summarized in Table 5 [4, 10 and 12].

When traveling on the 1 st class roads, the fuel consumption changed depending only on the driving speed. Column of vehicles drove fluently, however the driving speed did not exceed the value of $80 \mathrm{~km} / \mathrm{h}$. The impact of the lower temperature is remarkable, when the fuel consumption increased by $14.89 \%$ for the comparable driving conditions [6 and 13]

\section{Conclusion}

By optimizing the combustion process and using the catalysts, it is possible to reduce the amount of these harmful gases considerably; however, greenhouse gas $\mathrm{CO}_{2}$ cannot be eliminated by any catalyst. The only solution is to reduce the fuel consumption

The fuel consumption comparison while driving on the highway with the closed and open windows

Table 4

\begin{tabular}{|c|c|c|c|c|c|}
\hline \multicolumn{2}{|c|}{ Driving speed $[\mathrm{km} / \mathrm{h}]$} & \multicolumn{2}{|c|}{ Fuel consumption $[1 / 100 \mathrm{~km}]$} & \multirow[b]{2}{*}{$\begin{array}{l}\text { Index of increase in fuel } \\
\text { consumption }\end{array}$} & \multirow[b]{2}{*}{$\begin{array}{c}\text { Air temperature } \\
{\left[{ }^{\circ} \mathrm{C}\right]}\end{array}$} \\
\hline$[\mathrm{km} / \mathrm{h}]$ & $\begin{array}{l}\text { Index of increase in fuel } \\
\text { consumption compared to } \\
\text { the speed } 110 \mathrm{~km} / \mathrm{h}\end{array}$ & Closed windows & Open windows & & \\
\hline 110 & 1.00 & 5.2 & 5.3 & 1.019 & $34^{\circ} \mathrm{C}$ \\
\hline 120 & 1.091 & 5.7 & 5.8 & 1.018 & $34^{\circ} \mathrm{C}$ \\
\hline 130 & 1.182 & 6.8 & 7.0 & 1.029 & $34{ }^{\circ} \mathrm{C}$ \\
\hline
\end{tabular}

Source: Authors

The fuel consumption comparison while driving on the 1st class road

\begin{tabular}{|c|c|c|l|}
\hline Air temperature $\left[{ }^{\circ} \mathrm{C}\right]$ & Window & Fuel consumption $[1 / 100 \mathrm{~km}]$ & Conditions \\
\hline \multirow{2}{*}{$34{ }^{\circ} \mathrm{C}$} & \multirow{2}{*}{ Open } & 4.7 & column of vehicles, driving speed up to $80 \mathrm{~km} / \mathrm{h}$ \\
\cline { 3 - 4 } & & 4.9 & free road, driving speed up to $90 \mathrm{~km} / \mathrm{h}$ \\
\hline \multirow{2}{*}{$34^{\circ} \mathrm{C}$} & \multirow{2}{*}{ Open } & 4.7 & column of vehicles, driving speed up to $80 \mathrm{~km} / \mathrm{h}$ \\
\cline { 3 - 4 } & & 5.0 & free road, driving speed up to $90 \mathrm{~km} / \mathrm{h}$ \\
\hline $10{ }^{\circ} \mathrm{C}$ & Open & 5.4 & column of vehicles, driving speed up to $80 \mathrm{~km} / \mathrm{h}$ \\
\hline
\end{tabular}

Source: Authors 
of vehicles. The reduction of vehicles' fuel consumption can be achieved in several ways, for instance, by increasing the engine efficiency, reducing the driving resistances, optimizing the transport routes, and so on. During the vehicle's movement, resistances are acting against its free passage and trying to stop it. The engine of the vehicle must consume a certain amount of fuel to overcome these resistances. The size of individual driving resistances is not constant; but in the operating condition, it is variable according to the driving mode [14 - 17].

\section{Acknowledgement}

VEGA Project no. 1/0159/13 - KALASOVA, A. et al.: Basic Research of Telematic Systems, Conditions of Their Development and Necessity of Long-term Strategy. University of Zilina, the Faculty of Operation and Economics of Transport and Communications, 2013-2015.

\section{References}

[1] MACICA, J., FARKAS, P., KRILE, S.: Other Computational Technique for Estimation of Lower Bound on Capacity of TwoDimensional Diamond-1 Constrained Channel. Radioengineering, Prag, Check, vol. 18, No. 1, 2010, pp. 46-51. ISSN 1210-2512.

[2] LISCAK, S., RIEVAJ, V., SULGAN, M.: Vehical's Technical Condition and Emission. Eksploatacja i Niezawodnosc, vol. 37, No. 1, 2008, pp. 61-63. ISSN 1507-2711.

[3] RIEVAJ, V., MAJEROVA, Z.: How To Reduce Emissions Originated in Road Transport? Machines, Technologies, Materials, vol. 7, No. 6, 2013, pp. 24-27. ISSN 1313-0226.

[4] ZAMECNIK, J., JAGELCAK, J., VRABEL, J.: Influence of Drive Style on Petrol Consumption for Low-Volume Petrol Engine. MMK - Magnanimitas, 2014: Masaryk inter. conference for doctoral students and young scientists, Hradec Kralove, vol. 5, 2014, pp. 3211-3220. ISBN 978-80-87952-07-8.

[5] SARKAN, B., VRABEL, J.: Safety and Ecology of Road Vehicle Operation, $1^{\text {st }}$ ed., Bytca: Druska Books as university textbook, 106 p., 2014, ISBN 978-80-89646-92-0.

[6] RIEVAJ, V., MAJEROVA, Z.: Fuel Consumption in Road Transport as an Important Factor Influencing the Production of Greenhouse Gases, Technical Diagnostics of Machines and Production Equipment DIAGO 2015: 34. intern. conference, Ostrava: VSB - TU, 2015, pp. 114-119. ISSN 1210-311X.

[7] TOMASIKOVA, M., BRUMERCIK, F., NIEOCZYM, A.: Vehicle Simulation Model Criterion, Logi - Scientific J. on Transport and Logistics, vol. 6, No. 1, 2015, pp. 130-135. ISSN 1804-3216.

[8] DROZDZIEL, P., KRZYWONOS, L.: The Estimation of the Reliability of the First Daily Diesel Engine Start-Up during its Operation in the Vehicle. Maintenance and Reliability 2009, vol. 41, No. 1, pp. 4-10. ISSN 1507-2711.

[9] SKRUCANY, T., SARKAN, B., JAGELCAK, J.: Accelerator Position Impact on Fuel Consumption of Road Vehicles. Machines, Technologies, Materials, vol. 8, No. 5, 2014, pp. 16-18. ISSN 1313-0226.

[10] SARKAN, B., et al.: Possibilities of Measuring the Brake Specific Fuel Consumption in Road Vehicle Operation. QUAERE 2014: interdisciplinary intern. scientific conference of doctoral students and lecturers, Hradec Kralove, 2014. ISBN 978-80-87952-04-7.

[11] RIEVAJ, V., MAJEROVA, Z.: The Analysis of Selected Factors Influence on the Fuel Consumption. Asian J. of Engineering and Technology, vol. 3, No. 1, 2015, pp. 50-54. ISSN 2321-2462.

[12] NIEOCZYM, A.: Application of a Transportation Flux for Determining Qualitative Indices. Communications - Scientific Letters of the University of Zilina, vol. 7, No. 1, 2005, pp. 47-48. ISSN 1335-4205.

[13] FUTYU, I., GAL, G.: Implementing the Qualitative Consistency of Traffic Flows in Equilibrium Models, Logi - Scientific J. on Transport and Logistics, vol. 4, No. 1, 2013, pp. 40-52. ISSN 1804-3216.

[14] BRUMERCIK, F., KRZYWONOS, L.: Integrated Transportation System Simulation, Logi - Scientific J. on Transport and Logistics, vol. 4, No. 2, 2013, pp. 05-10. ISSN 1804-3216.

[15] STOPKA, O., BARTUSKA. L., KAMPF, R.: Passengers' Evaluation of the Integrated Transport Systems, Our Sea, vol. 62, 2015, pp. 153-157. ISSN 0469-6255.

[16] FEDORKO, G., HUSAKOVA, N., DUDAS, G.: Design of Allocation of New Technological Equipment Within the Frame of Production Process in Company Getrag Ford Transmissions Slovakia, Acta Montanistica Slovaca, vol. 15, 2010, pp. 14-22.

[17] JAGELCAK, J., KUBASAKOVA, I.: Load Distribution in General Purpose Maritime Container and the Analysis of Load Distribution on Extendable Semitrailer Container Chassis Carrying Different Types of Containers, Our Sea, vol. 61, No.5-6, 2014, pp. 106-116. ISSN 0469-6255. 